\title{
The changing scene of preoperative coronary diagnostics
}

\author{
Saswata Deb, MD, and Stephen E. Fremes, MD
}

See related article on pages $1622-8$

Current data supporting coronary artery bypass grafting surgery $(\mathrm{CABG})$ versus percutaneous coronary intervention (PCI) have been derived from studies in which the extent and severity of angiographic stenoses were largely based on visual inspection of the coronary anatomy. ${ }^{1,2}$ Whereas decisions of target vessel revascularization have typically been predicated on this diagnostic modality, the use of physiologically based hemodynamic effects of stenosis using fractional flow reserve (FFR) has rapidly emerged for PCI. ${ }^{3-6}$ A recent meta-analysis ${ }^{7}$ of 19 studies concluded that it was safe to defer PCI based on negative FFR results. Another meta-analysis ${ }^{8}$ that included the 2-year results from the Fractional Flow Reserve versus Angiography for Multivessel Evaluation study ${ }^{5}$ concluded that PCI should only be performed in the presence of hemodynamically significant lesions according to FFR. These findings support both the American (class IIA) and European (class IA) guidelines that recommend FFR for guiding percutaneous coronary revascularization. ${ }^{8-10}$ In CABG, the application of FFR in deciding whether to bypass selected targets is not yet clear. ${ }^{11}$ The lack of clarity could be due to the differences between PCI and CABG. The risks of performing unnecessary PCI may outweigh the risks of additional grafts; graft failure or string sign of a graft to a target with a mild stenosis may not be as clinically important as stent failure of a similar native vessel. Furthermore, staged PCI is easier to perform than staged CABG.

In this issue of the Journal of Thoracic and Cardiovascular Surgery, Honda and colleagues ${ }^{12}$ present the results of their investigation into the relationship between the preoperative severity of FFR for mild-to-moderate stenosis by visual inspection and intra- and postoperative graft characteristics. More specifically, they investigated 72 in-situ internal thoracic arteries (ITAs) (left $\mathrm{n}=58$ and right $\mathrm{n}=14$ ) grafted to the left anterior descending artery; each left anterior

\footnotetext{
From the Schulich Heart Centre, Sunnybrook Health Sciences Centre, University of Toronto, and Toronto Ontario Institute of Health Policy Management and Evaluation, University of Toronto, Toronto, Ontario, Canada.

Disclosure: Authors have nothing to disclose with regard to commercial support

Received for publication March 9, 2015; accepted for publication March 10, 2015; available ahead of print April 11, 2015

Address for reprints: Stephen E. Fremes, MD, Schulich Heart Centre, Sunnybrook Health Sciences Centre, University of Toronto, 2075 Bayview Ave, Room H405,

Toronto, ON, Canada M4N 3M5 (E-mail: stephen.fremes@sunnybrook.ca).

J Thorac Cardiovasc Surg 2015;149:1629-30

$0022-5223 / \$ 36.00$

Copyright (c) 2015 by The American Association for Thoracic Surgery http://dx.doi.org/10.1016/j.jtcvs.2015.03.014
}

descending artery was preoperatively stratified as severe functional stenosis (group S: FFR $<0.70 ; \mathrm{n}=44)$, mild functional stenosis (group M: $0.70 \leq$ FFR $<$

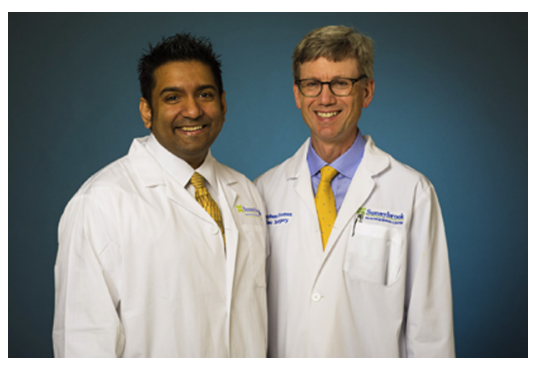
$0.75 ; \mathrm{n}=14$ ), or functionally nonstenotic (group N: FFR $\geq 0.75 ; \mathrm{n}=14$ ). They reported better intraoperative graft flow parameters to target vessels with more severe functional stenosis, and highlighted the presence of competitive flow in mild functional coronary stenosis. Whereas all patients left the operating room with patent grafts, postoperatively a distal thread sign was present in $50 \%$ in group $\mathrm{N}$ and $4.2 \%$ in group $\mathrm{S}$; the latter group also had a failed ITA graft.

The strengths of this study include the simple, statistically sound design and the use of objective techniques to assess intraoperative graft flow parameters using transit time flow (TTF) measurements and indocyanine green fluorescence along with assessment of postoperative graft status with computed tomography (CT) $(n=65)$ or magnetic resonance imaging for those with renal dysfunction $(\mathrm{n}=2)$ within 1 year. The study also had multiple limitations. Studies have shown that although TTF can predict early graft failure, cutoff values are not yet clear. ${ }^{13,14}$ It has been suggested that both TTF and indocyanine green fluorescence are valuable at identifying extremes (ie, occluded or patent), but neither is specific or sensitive at identifying subtle abnormalities. ${ }^{15}$ Furthermore, a distal thread sign was seen in $50 \%$ of group $\mathrm{N}$ patients, which could be speculated to be due to competitive flow. However, the overall incidence of thread sign was much higher than expected in 11 out of $72(15.2 \%)$ ITAs within 1 year; this was assessed mostly by CT scan, which may not be ideal to detect such phenomena. This study was also limited by small numbers and the biases associated with a retrospective study. Furthermore, it included combined procedures that could affect intraoperative results.

Despite these limitations, Honda and colleagues ${ }^{12}$ highlight a potentially important area in cardiac surgery-the use of FFR in CABG. Although the literature is limited, a recent observational study by Toth and colleagues ${ }^{16}$ involving 627 patients reported that FFR-guided CABG was associated with fewer graft anastomoses and a lower rate of on-pump surgery and angina compared with angiography-guided CABG. Botman and colleagues ${ }^{17}$ 
studied 164 patients and reported an occlusion rate of $8.9 \%$ in bypass grafts with functionally significant lesions compared with $21.4 \%$ of the functionally nonsignificant lesions at 1 year. Furthermore, the study by Honda and colleagues ${ }^{12}$ sheds light on the early graft flow characteristics based on the functional stenosis severity of the native vessel. These studies support the notion that the nature of stenosis (anatomic vs functional) is important in surgical revascularization. ${ }^{11}$ Such findings further reinforce the importance of the heart team approach for patients with multivessel disease. Moreover, as further studies, including the third Fractional Flow Reserve versus Angiography for Multivessel Evaluation study, ${ }^{18}$ continue to evolve and noninvasive methods of FFR are developed, including $\mathrm{CT}^{19}$ and magnetic resonance imaging, ${ }^{20}$ there stands a likely possibility that coronary disease will be reclassified from anatomic to functional, which may change indications altogether for surgical revascularization in the future. ${ }^{11}$

\section{References}

1. Mohr FW, Morice MC, Kappetein AP, Feldman TE, Stahle E, Colombo A, et al. Coronary artery bypass graft surgery versus percutaneous coronary intervention in patients with three-vessel disease and left main coronary disease: 5-year follow-up of the randomised, clinical SYNTAX trial. Lancet. 2013;381:629-38.

2. Farkouh ME, Domanski M, Sleeper LA, Siami FS, Dangas G, Mack M, et al. Strategies for multivessel revascularization in patients with diabetes. $N$ Engl J Med. 2012;367:2375-84.

3. De Bruyne B, Fearon WF, Pijls NH, Barbato E, Tonino P, Piroth Z, et al. Fractional flow reserve-guided PCI for stable coronary artery disease. $N$ Engl J Med. 2014;371:1208-17.

4. De Bruyne B, Pijls NH, Kalesan B, Barbato E, Tonino PA, Piroth Z, et al. Fractional flow reserve-guided PCI versus medical therapy in stable coronary disease. N Engl J Med. 2012;367:991-1001.

5. Pijls NH, Fearon WF, Tonino PA, Siebert U, Ikeno F, Bornschein B, et al. Fractional flow reserve versus angiography for guiding percutaneous coronary intervention in patients with multivessel coronary artery disease: 2-year follow-up of the FAME (Fractional Flow Reserve Versus Angiography for Multivessel Evaluation) study. J Am Coll Cardiol. 2010;56:177-84.

6. Tonino PA, De Bruyne B, Pijls NH, Siebert U, Ikeno F, van't Veer M, et al. Fractional flow reserve versus angiography for guiding percutaneous coronary intervention. N Engl J Med. 2009;360:213-24.
7. Nascimento BR, Belfort AF, Macedo FA, Sant'Anna FM, Pereira GT, Costa MA, et al. Meta-analysis of deferral versus performance of coronary intervention based on coronary pressure-derived fractional flow reserve. Am J Cardiol. 2015;115:385-91.

8. Zhang D, Lv S, Song X, Yuan F, Xu F, Zhang M, et al. Fractional flow reserve versus angiography for guiding percutaneous coronary intervention: a meta-analysis. Heart. 2015;101:455-62.

9. Levine GN, Bates ER, Blankenship JC, Bailey SR, Bittl JA, Cercek B, et al. 2011 ACCF/AHA/SCAI guideline for percutaneous coronary intervention. A report of the American College of Cardiology Foundation/American Heart Association Task Force on Practice Guidelines and the Society for Cardiovascular Angiography and Interventions. J Am Coll Cardiol. 2011;58:e44-122.

10. Wijns W, Kolh P, Danchin N, Di Mario C, Falk V, Folliguet T, et al. Guidelines on myocardial revascularization. Eur Heart J. 2010;31:2501-55.

11. Ferguson TB Jr, Chen C, Buch AN. Fractional flow reserve-guided coronary bypass surgery: should surgeons use it? Curr Opin Cardiol. 2013;28: 654-60.

12. Honda K, Yoshitka O, Yoshiharu N, Uchita S, Yuzaki M, Kaneko M, et al. Graft flow assessment using transit time flow meter in FFR-guided coronary artery bypass surgery. J Thorac Cardiovasc Surg. 2015;149:1622-8.

13. Une D, Deb S, Chikazawa G, Kommaraju K, Tsuneyoshi H, Karkhanis R, et al. Cut-off values for transit time flowmetry: are the revision criteria appropriate? J Card Surg. 2013;28:3-7.

14. Jokinen JJ, Werkkala K, Vainikka T, Perakyla T, Simpanen J, Ihlberg L. Clinical value of intra-operative transit-time flow measurement for coronary artery bypass grafting: a prospective angiography-controlled study. Eur J Cardiothorac Surg. 2011;39:918-23.

15. Leacche M, Balaguer JM, Byrne JG. Intraoperative grafts assessment. Semin Thorac Cardiovasc Surg. 2009;21:207-12.

16. Toth G, De Bruyne B, Casselman F, De Vroey F, Pyxaras S, Di Serafino L, et al. Fractional flow reserve-guided versus angiography-guided coronary artery bypass graft surgery. Circulation. 2013;128:1405-11.

17. Botman CJ, Schonberger J, Koolen S, Penn O, Botman H, Dib N, et al. Does stenosis severity of native vessels influence bypass graft patency? A prospective fractional flow reserve-guided study. Ann Thorac Surg. 2007;83: 2093-7.

18. Fearon WF, Zimmermann FM. A Comparison of Fractional Flow Reserve-Guided Percutaneous Coronary Intervention and Coronary Artery Bypass Graft Surgery in Patients With Multivessel Coronary Artery Disease (FAME 3). https://www.clinicaltrials.gov/ct2/show/NCT02100722. Accessed March 3, 2015.

19. Al-Hassan D, Leipsic J. Noninvasive fractional flow reserve derived from coronary computed tomography angiography: integrated anatomical and functional assessment. Future Cardiol. 2013;9:243-51.

20. Deng Z, Fan Z, Xie G, He Y, Natsuaki Y, Jin N, et al. Pressure gradient measurement in the coronary artery using 4D PC-MRI: towards noninvasive quantification of fractional flow reserve. J Cardiovasc Magn Reson. 2014; 16:O55. 